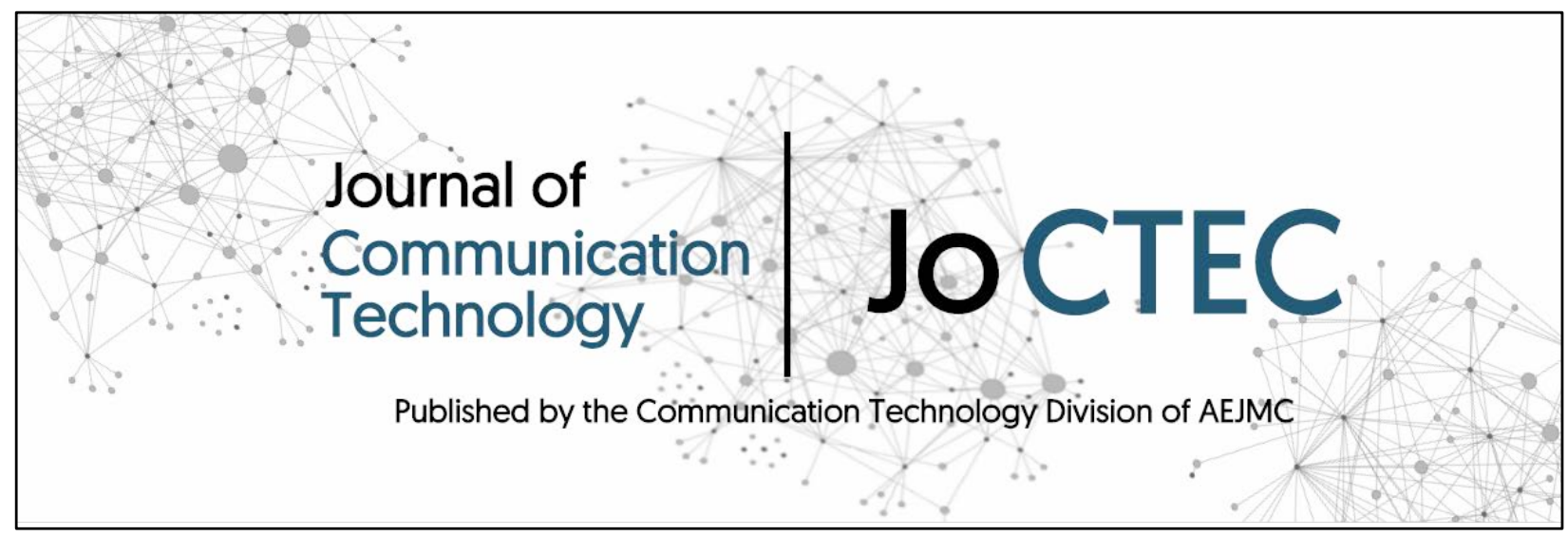

Does Customization Benefit Brand Evaluation When Consumers Experience Psychological Uncertainty?

\author{
Dr. Linwan Wu \\ Assistant Professor \\ School of Journalism and Mass Communication \\ University of South Carolina
}

Correspondence:

803-777-0771

LINWANWU@mailbox.sc.edu

Original manuscript accepted for publication in Journal of Communication Technology

Published by the Communication Technology Division of the Association for Education in Journalism and Mass Communication

DOI: 10.51548/joctec-2019-001 


\title{
Does Customization Benefit Brand Evaluation When Consumers Experience Psychological Uncertainty?
}

\begin{abstract}
The online environment is filled with uncertain situations. Although digital interface plays an important role in online information processing, limited research has explored whether digital interface could influence how consumers deal with the psychological state of uncertainty in the online environment. The present study focuses on customization as an important feature of digital interface. A lab experiment was conducted to analyze the interplay between psychological uncertainty, interface customization, and the individual trait of uncertainty avoidance on consumers' online brand evaluation. The results indicated that participants with a strong tendency of uncertainty avoidance evaluated a brand on a customized website more favorably than a non-customized website when they experienced psychological uncertainty. Such effects were not observed among participants with a weak tendency of uncertainty avoidance.

Keywords. Customization, psychological uncertainty, uncertainty avoidance, brand evaluation, digital media
\end{abstract}


"The world is an uncertain place" (van den Bos, Poortvliet, Maas, Miedema, \& van den Ham, 2005, p. 93). People may experience uncertainty in everyday life due to a variety of reasons, such as having a new job, moving to a new place, or starting a new relationship. Existing consumer research has primarily studied uncertainty as a characteristic of the decision environment, such as the uncertainty associated with adopting innovative products, discovering that uncertainty has negative impact on consumer responses (Castaño, Sujan, Kacker, \& Sujan, 2008; Kleijnen, Lee, \& Wetzels, 2009). Recent investigations in consumer psychology started to focus on consumers' psychological state of uncertainty, which is not necessarily related to purchasing decisions (Faraji-Rad \& Pham, 2017). Psychological uncertainty is uncomfortable and sometimes even threatening (Grieve \& Hogg, 1999; Hogg, 2007), because it indicates people's lack of conviction of their own beliefs, feelings, or behaviors (McGregor, Zanna, Holmes, \& Spencer, 2001). In the consumer context, psychological uncertainty has been found to negatively influence people's product/brand evaluations (Faraji-Rad \& Pham, 2017).

It is an innate motivation of human beings to seek for some way of reducing the feelings of uncertainty (van den Bos, 2009; van den Bos et al., 2005). In e-commerce, digital interface plays an irreplaceable role in consumers' processing of product/brand information. Previous research of communication technology has demonstrated that the features of digital interface, such as interactivity and customization, have significant psychological effects on individual users (see Waddell, Zhang, \& Sundar, 2016), making the researcher wonder if digital interface may influence how people deal with their psychological uncertainty. The present study aims to answer this question by focusing on customization in the context of online brand evaluation. Previous research has confirmed that customization helps users reaffirm their sense of self (Sundar, 2008). Since psychological uncertainty threatens the sense of self (McGregor et al., 
2001), it is possible that customization may help eliminate psychological uncertainty and improve brand evaluation in the online environment.

People are different in terms of tolerating the status of uncertainty. The concept of uncertainty avoidance indicates the individual difference in perceiving the status of uncertainty as threatening (Hofstede, 2001). Specifically, individuals with strong uncertainty avoidance are more likely to perceive uncertainty as threatening and are more easily motivated to reduce such feelings compared to those who have a weak tendency of uncertainty avoidance. Therefore, the effects of customization on brand evaluation under psychological uncertainty may only be pronounced among consumers with a strong tendency of uncertainty avoidance.

In summary, the present study aims to investigate the interplay between psychological uncertainty, interface customization, and the individual trait of uncertainty avoidance on consumers' online brand evaluations. Theoretically, this study will contribute to the literature of communication technology and digital marketing by identifying the boundary conditions of the impact of customization on consumer responses. Practically, this study will provide useful suggestions to online marketers with regard to employing customization services strategically.

\section{Customization}

As an important feature of digital interface, customization has been widely investigated by previous research in computer-mediated communication. Customization refers to the "userinitiated activities, which allow the user to actively change the interface or regulate information that they receive using a set of options provided by a media system" (Kang \& Sundar, 2013, p. 2274; Wind \& Rangaswamy, 2001). Customization allows users to modify the format and content of digital media based on their own values and preferences. According to the agency model of customization, the crucial meaning of customization is that a user becomes part of the 
information source (Sundar, 2008). The media content as a result of customization thus reflects some facets of the self (Kalyanaraman \& Sundar, 2006; Petty, Barden, \& Wheeler, 2002; Sundar, 2008).

The relationship between customization and the self has been examined by previous research (Kang \& Sundar, 2013, 2016). The key finding is that customization "offers a vehicle for the user to assert his/her identity" (Sundar, 2008, p. 68). Individuals normally make changes of the media interface in accordance with what they like and what they believe either consciously or unconsciously (Sundar et al., 2012). The procedure and outcomes of customization thus more or less reflect users' values, beliefs, preferences, and personalities, which are all important composites of their self-identities (Kang \& Sundar, 2016). In the digital environment, people often express their identities by presenting self-images online (Marathe \& Sundar, 2011). Given that customization helps build one's connection with online information, it is reasonable to believe that customization has the ability to affirm a user's self-identity (Marathe \& Sundar, 2011).

The principle of self-affirmation explains why customization gives rise to satisfying human-computer interactions. Sundar and Marathe (2010) argued that "the sense of me-ness" experienced by users during the process of customization makes them believe that the media content represents their identities and thus results in beneficial communication effects. In addition, customization may help extend one's self to the media interface or media content (Lee \& Sundar, 2015; Valenzuela, Dhar, \& Zettelmeyer, 2009). According to the theoretical framework of the extended self (Belk, 1988, 2013), people tend to evaluate the extension of themselves in a favorable manner.

\section{Uncertainty and Consumer Experience}


Uncertainty is a psychological state "characterized by a discrepancy between [an individual's] cognitive structures and perceptions" (Faraji-Rad \& Pham, 2017, p. 2). In other words, uncertainty occurs when people's conviction of their cognitions, feelings, or behaviors is challenged by what they perceive in the environment (Hogg, 2000). The status of uncertainty is undesirable (Grieve \& Hogg, 1999; Hogg, 2007; Van den Bos et al., 2005), as it indicates difficulty of predicting happenings and making plans, which signifies one's reduced control over his/her life (Hogg, 2000; Hogg \& Adelman, 2013). Uncertainty also "deprives one of confidence in how to behave and what to expect from the physical and social environment within which one finds oneself" (Van den Bos et al., 2005, p. 93). When experiencing uncertainty, people are often motivated to perform behaviors that help them regain feelings of certainty (Hogg, 2000; Van den Bos, 2009; Van den Bos \& Lind, 2002).

Uncertainty is not uncommon for consumers. Various aspects of consumer experience are associated with uncertainty, including consequences of buying products, information needed for making decisions, and alternatives available for exercising selections (Johnson, 2004). Uncertainty is also salient when consumers are facing innovative products (Hoeffler, 2003; Littler \& Melanthiou, 2006). It is "widely documented as barriers to innovation adoption" (Castaño et al., 2008, p. 321). For example, uncertainty existing in the process of adopting innovative technological products may lead consumers to resisting such innovations or postponing their purchases (Antioco \& Kleijnen, 2010; Kleijnen et al. 2009; Szmigin \& Foxall, 1998). In the existing literature of consumer research, uncertainty is often paralleled with the discussion of consumption risks (e.g., Dowling \& Staelin, 1994). That is to say uncertainty normally gives rise to discomfort and undesired shopping experience.

\section{Psychological Uncertainty and Self}


While previous consumer research has demonstrated the detrimental influences of uncertainty associated with certain decision environments (e.g., adopting an innovative product), relatively limited attention has been paid to consumers' psychological state of uncertainty which is not directly related to a purchase decision. As suggested by Faraji-Rad and Pham (2017), psychological uncertainty inserts significant impact on consumer behaviors through one's sense of self. Individuals' beliefs, feelings, and behaviors are the important components of their selfconcepts (Hogg, 2000). Given that people who experience psychological uncertainty lack the conviction of what they believe and what they do, their sense of self is threatened by the status of uncertainty (Hogg, 2001; Faraji-Rad \& Pham, 2017; McGregor et al., 2001; van den Bos, 2009). Accordingly, an effective strategy of coping with the discomfort brought by psychological uncertainty is to reaffirm the self (Faraji-Rad \& Pham, 2017; McGregor et al., 2001; Steele \& Liu, 1983). Existing research has shown the effects of psychological uncertainty on individuals' behaviors of reaffirming their self-identities. For example, psychological uncertainty was found to give rise to a strong attachment to one's own religion (McGregor et al., 2008) and a greater tendency to favor one's own group (Grieve \& Hogg, 1999). In addition, McGregor et al. (2001) discovered that the motivation of self-affirmation faded when participants were provided with opportunities to express their own identities or values. In consumer research, Faraji-Rad and Pham (2017) discovered that the prime of uncertainty threatened consumers' self-perceptions and thus led to stronger preferences to affective rather than non-affective elements when assessing brands/products because "affect has high subjective validity" (p. 3, see also Zajonc, 1980). In other words, affective elements are weighted more in product evaluation under psychological uncertainty because they are used to reaffirm consumers' self-identities.

\section{Uncertainty Avoidance}


Although human beings tend to avoid the status of uncertainty in general, some people may be more tolerant to the situations that trigger feelings of uncertainty than others (Hogg, 2007). Previous research has discovered that some biological traits may shape individuals' perceptions and behaviors when they deal with uncertain situations (Sorrentino, Hodson, \& Huber 2001; Webster \& Kruglanski, 1997). One important individual factor identified by previous studies is people's tendency of uncertainty avoidance (Hogg, 2000; Van den Bos, 2009). Uncertainty avoidance, which refers to the extent to which people "feel threatened by uncertain or unknown situations" (Hofstede, 2001, p. 161), was first introduced as one dimension in Hofstede's (2001) model of cultural values. Later studies applied this concept to the individual level, conceptualizing and measuring uncertainty avoidance as a psychological factor that varies from person to person (Wu, 2017; Yoo, Donthu, \& Lenartowicz, 2011). Individuals with a strong tendency of uncertainty avoidance have a greater motivation to get rid of the status of uncertainty as well as to predict and control their environment than those with a weak tendency of uncertainty avoidance (Griffith, Hu, \& Ryans, 2000; Wu, 2017). Since uncertainty threatens one's sense of self (Faraji-Rad \& Pham, 2017; van den Bos, 2009), it is likely that consumers with strong uncertainty avoidance are more responsive to the opportunities of reaffirming their self-identities when assessing products/brands compared to those with weak uncertainty avoidance.

\section{Hypotheses Development}

The present study aims to investigate the influence of interface customization on coping with consumers' psychological uncertainty when evaluating brands online. The status of uncertainty is undesirable as it blurs one's perception of self (Hogg, 2001). Accordingly, consumers' brand assessment may be vulnerable to their psychological state of uncertainty. 
Since customization helps affirm one's self-identity (Sundar, 2008), this study predicts that customization would benefit brand evaluation by allowing consumers to assert conviction and restore feelings of certainty. This is consistent with the notion of certainty compensation in the self-affirmation theory (Steele, 1988) and the uncertainty-identity theory (Hogg, 2007), which argues that individuals' feelings of uncertainty in one domain can be compensated for by regaining certainty or conviction from another domain (McGregor et al., 2001; McGregor \& Marigold, 2003). That is, even though one's psychological uncertainty is incidental to interacting with digital interface (e.g., a website), the process of customizing the interface would generate feelings of certainty to compensate for such psychological uncertainty. Given that customization builds a strong connection between a user and media content (Sundar \& Marathe, 2010), consumers may unconsciously take the brand presented on a customized website as part of the agent that empowers them to regain sense of certainty, thus evaluating the brand in a favorable manner. Since consumers with a strong tendency of uncertainty avoidance are motivated to stay away from the status of uncertainty to a greater extent than their counterparts with a weak tendency of uncertain avoidance, the former may be more likely to rely on customization to regain feelings of certainty than the latter. Therefore, the current study predicts that the positive influence of customization on brand evaluation under psychological uncertainty will only be observed among consumers with a strong tendency of uncertainty avoidance. Formally, the following hypothesis is proposed.

H1: Among consumers with strong uncertainty avoidance, customization will positively influence brand attitude when these consumers experience psychological uncertainty. In addition, this study also expects to explore why customization benefits brand evaluation under psychological uncertainty. As discussed previously, uncertainty threatens one's 
sense of self (Hogg, 2001; van den Bos, 2009), while customization helps reaffirm one's selfidentity (Sundar, 2008). Therefore, perceived identity is expected to be an underlying mechanism of customization. However, ambiguous self-perception is not the only consequence of psychological uncertainty. The psychology literature suggests that uncertainty may also trigger feelings of reduced control over one's environment (Hogg, 2000; Hogg \& Adelman, 2013). Existing research on customization has confirmed that the process of modifying the content and layout of digital interface makes users feel in control (Sundar, 2008). As a result, someone's perceptions of reduced control caused by psychological uncertainty may be (partially) resolved by customizing digital interface. Perceived identity and sense of control have been previously examined as the underlying mechanisms of customization (Marathe \& Sundar, 2011). However, they have not been tested as the mechanisms accounting for the effects of customization on brand evaluation. Marathe and Sundar (2011) analyzed different patterns of these mechanisms and found that perceived identity fully mediated the relationship between customization and sense of control. This indicated that "sense of identity is the main reason why those who engage in customization feel a sense of control" (Marathe \& Sundar, 2011, p. 787). In other words, perceived identity seems to be the antecedent of one's control perceptions during the process of customization. Therefore, this study proposes a serial mediation from perceived identity to sense of control as the underlying mechanisms of the impact of customization on brand attitude. Formally, the following hypothesis is proposed.

H2: Perceived identity and sense of control will mediate the relationship between customization and brand attitude in a serial way (i.e., customization $\rightarrow$ perceived identity $\rightarrow$ sense of control $\rightarrow$ brand attitude).

\section{Method}




\section{Study Design}

To test the hypotheses, a lab experiment was conducted adopting a 2 (psychological status: uncertainty vs. certainty) $\times 2$ (interface: customization vs. non-customization), betweensubjects factorial design with uncertainty avoidance measured as a continuous independent variable. Psychological uncertainty and interface customization were experimentally manipulated. Participants were randomly assigned to one of the four experimental conditions.

\section{Participants}

One hundred and twenty-one $(N=121)$ undergraduate students from a large southeastern university in the United States were recruited to take part in this experiment. Among these participants, $19.8 \%$ were male $\left(N_{\text {male }}=24\right)$, and $80.2 \%$ were female $\left(N_{\text {female }}=97\right)$. The mean age of participants was $20.68(\mathrm{SD}=2.31)$. As for race, $81.0 \%(N$ White $=98)$ were White, $11.6 \%$ $\left(N_{\text {African American }}=14\right)$ were African American, and 3.3\% $\left(N_{\text {Asian }}=4\right)$ were Asian.

\section{Stimulus materials}

Manipulation of psychological uncertainty. Participants' psychological status was primed following previous research (e.g., Faraji-Rad \& Pham, 2017; Van den Bos et al., 2005). In the uncertainty condition, participants were asked to write down a past situation in which they felt strongly uncertain. In the certainty condition, participants were asked to write down a past situation in which they felt strongly certain. A pretest $(N=55)$ was conducted among a group of undergraduate students from the same university who did not participate in the main experiment. The results of the pretest indicated that the manipulation had a significant effect on perceived certainty, such that participants in the uncertainty condition $(M=6.72, \mathrm{SD}=1.58)$ perceived less certainty than those in the certainty condition $(M=7.70, \mathrm{SD}=1.57), F(1,53)=5.39, p=.024$, $\omega_{\mathrm{p} 2}=0.07$. The manipulation also had a significant effect on self-concept clarity, such that 
participants in the uncertainty condition $(M=5.26, \mathrm{SD}=1.61)$ perceived less clarity of their selfconcept than those in the certainty condition $(M=6.14, \mathrm{SD}=1.40), F(1,53)=4.70, p=.035$, $\omega_{\mathrm{p} 2}=0.06$. Self-concept clarity was measured for checking the fundamental assumption that psychological uncertainty blurs one's sense of self (Hogg, 2001) and the aforementioned result confirmed this assumption. In addition, the manipulation did not have a significant effect on selfefficacy, $F(1,53)=0.32, p=.573$, or self-esteem, $F(1,53)=0.21, p=.647$. These two variables were included in the pretest as confounding checks since they were related to, but different from self-concept clarity. The non-significant results indicated that the prime of psychological uncertainty did not make participants question their abilities or influence participants' subjective evaluation of their own worth.

Manipulation of customization. Customization was manipulated following previous research (e.g., Kang \& Sundar, 2013, 2016). The online web portal, igHome (www.ighome.com), was employed as the website for the manipulating customization. igHome provides users with similar functions as iGoogle. Users of igHome are allowed to customize the interface by adding or removing various gadgets and changing different themes. In the customization condition, participants were asked to customize the interface of igHome to make it best reflect their own values and personalities. In the non-customization condition, participants were asked to only browse the information presented on the igHome interface without changing the appearance of the webpage. See Appendix for examples of customized and non-customized webpages.

Brand article. All the participants in the main experiment read an article about a fictitious airline brand, FlyAway, after the manipulation of customization. This brand article was edited based on a real one from the Brand Studio of the New York Times. The article was mainly about how the airline provides high quality service to its customers. 


\section{Procedure}

Before conducting the experiment, the research assistants created 20 igHome accounts and set up the interface associated with each account. Each igHome webpage was set to contain the same gadgets (i.e., the default interface), including Google News, ESPN, Weather Forecast, Yahoo News, TV Guide, and Popular Science. The layout of these gadgets was also identical across all the accounts. The experiment was conducted in a university computer lab during a three-week time period. Upon their arrival at the lab, participants were randomly assigned to one of the four experimental conditions. At the beginning of the experiment, participants wrote down their past experiences of uncertainty or certainty for three minutes. Their perceptions of certainty were measured right after that. Then participants were taken to the igHome website to either customize the interface or browse the information on it for ten minutes. After that, participants reported their perceived identity and sense of control. The task of interacting with the website along with the measures of perceived identity and sense of control were masked as a separate study from the writing task (i.e., the manipulation of psychological uncertainty). Then participants moved to the final stage of the experiment, in which they were asked to add the brand article to their igHome webpages through a RSS feed and they were instructed to read this article on the igHome interface. After finishing reading the article, participants reported their attitude toward the brand, uncertainty avoidance, product involvement, and some demographic information. This final stage was presented to participants under the guise of another separate study. At the end of the experiment, participants were thanked and debriefed. The entire process took approximately 25 minutes. After participants left, the research assistants saved the screenshots of all the igHome webpages and reset all the accounts to the default layout.

\section{Measures in the Pretest}


All measures in the pretest and the main experiment used a nine-point scale ranging from 1 to 9 unless otherwise stated.

Perceived certainty. Participants' perceived certainty was measured adopting a three-item scale from Faraji-Rad and Pham (2017). The items were "unsure/sure," "don't feel confident/feel confident," and "hesitant/determined." The scale was reliable (Cronbach's alpha =0.91).

Self-concept clarity. Self-concept clarity was measured adopting a 12-item scale from Campbell et al. (1996). An example item was "My beliefs about myself often conflict with one another." The scale was reliable (Cronbach's alpha $=0.88)$.

Self-efficacy. Self-efficacy was measured adopting a six-item scale from Romppel et al. (2013). An example item was "If someone opposes me, I can find means and ways to get what I want.” The scale was reliable (Cronbach's alpha $=0.89)$.

Self-esteem. Self-esteem was measured adopting a ten-item scale from Rosenberg (1965). An example item was "On the whole, I am satisfied with myself." The scale was reliable (Cronbach's alpha $=0.88)$.

In order to check the discriminant validity between variables measured in the pretest, the correlations between all the measured variables were tested (see Table 1). A scrutiny of the correlation table indicated that none of the correlations exceeded 0.7. Since a correlation greater than 0.7 indicates a majority of shared variance $(0.7 \times 0.7=49 \%$ shared variance $)$ (Ibrahim Shiratuddin, \& Wong, 2015), the discriminant validity of the measures in this pretest was acceptable.

Insert Table 1 about here.

\section{Measures in the Main Experiment}


Perceived certainty. Perceived certainty in the main experiment was measured using the identical scale in the pretest. The Cronbach's alpha is 0.92 .

Perceived identity. Participants' perceived identity was measured using a five-item scale adopted from Kang and Sundar (2016). An example item was "The website was a true representation of who I am." The scale was reliable (Cronbach's alpha $=0.94)$.

Sense of control. Participants' sense of control was measured adopting ten items from Marathe and Sundar (2011). An example item was "I was able to control my interaction with the website." The scale was reliable (Cronbach's alpha =0.92).

Attitude toward the brand. Participants' attitude toward the brand were assessed using a seven-item scale adopted from previous research (Li \& Kalyanaraman, 2012). Some examples items included "appealing/unappealing," "favorable/unfavorable," and "unattractive/attractive." The scale was reliable (Cronbach's alpha $=0.92)$.

Uncertainty avoidance. Participants' uncertainty avoidance was measured adopting a five-item scale from Yoo et al. (2011). An example item was "It is important to have instructions spelled out in detail so that I always know what I'm expected to do." The scale was reliable $($ Cronbach's alpha $=0.92)$.

Product involvement. Product involvement was measured adopting items from Zaichkowsky (1994). It was added as a control variable for ensuring that participants' involvement with airline services would not account for the final results. The scale included three items. These items were "relevant/irrelevant," "means nothing to me/means a lot to me," and "not needed/needed." The scale was reliable (Cronbach's alpha $=0.81$ ). 
The correlations between all the measured variables in the main experiment were tested to check the discriminant validity between variables (see Table 2). The results indicated that the discriminant validity of the measures in the main experiment was acceptable.

Insert Table 2 about here.

\section{Results}

\section{Manipulation Check}

Perceived certainty. A two-way ANOVA test was conducted to check the manipulation of psychological uncertainty in the main experiment. The results indicated that the manipulation had a significant effect on participants' perceived certainty, such that those in the uncertainty condition $(M=5.07, \mathrm{SD}=2.30)$ perceived less certainty than those in the certainty condition $(M$ $=7.14, \mathrm{SD}=2.00), F(1,117)=27.49, p=.000, \omega_{\mathrm{p} 2}=0.18$. Moreover, there was no main effect of customization, $F(1,117)=1.40, p=.240$, nor interaction effect between uncertainty and customization on perceived certainty, $F(1,117)=0.47, p=.493$. Therefore, the manipulation was successful.

Customization. To check the manipulation of customization, the research assistants accounted the number of changes $(M=5.32, \mathrm{SD}=5.88)$ each participant made on the igHome interface. Specifically, the research assistants compared the screenshot of each participant's webpage with the default interface. One change was counted if a participant (1) added a gadget that was not on the default interface, (2) deleted a gadget that was on the default interface, or (3) altered the background theme. The intercoder reliability was desirable (Krippendorff's alpha $($ ratio $)=0.958)$. A two-way ANOVA test found that the manipulation had a significant effect on the changes participants made on the igHome interface, such that those in the customization condition $(M=10.26, \mathrm{SD}=4.10)$ made significantly more changes on the interface than those in 
the non-customization condition $(M=0.14, \mathrm{SD}=0.57), F(1,117)=349.99, p=.000, \omega_{\mathrm{p} 2}=0.75$. Moreover, there was no main effect of uncertainty, $F(1,117)=1.08, p=.301$, nor interaction effect between customization and uncertainty on number of changes made on the interface, $F(1$, $117)=0.26, p=.610$. Therefore, the manipulation was successful.

\section{Hypotheses Testing}

Hypothesis 1 predicts a three-way interaction effect between psychological uncertainty, customization, and uncertainty avoidance on participants' brand attitude. A moderated moderation analysis with 5,000 bootstrapped samples was conducted using model 3 of the PROCESS macro for SPSS (Hayes, 2012). Uncertainty was coded as 1, and certainty was coded as 2. Non-customization was coded as 1 , and customization was coded as 2 . Product involvement was added as the covariate. The results revealed a significant three-way interaction effect between psychological uncertainty, customization, and uncertainty avoidance on brand attitude, $F(1,112)=6.54, p=.012, R_{2 \text { change }}=0.04$. Among participants with weak uncertainty avoidance, there was not a significant two-way interaction effect between uncertainty and customization on brand attitude, $F(1,112)=0.05, p=.825$. Among participants with strong uncertainty avoidance, there was a significant two-way interaction effect between uncertainty and customization on brand attitude, $F(1,112)=11.08, p=.001$. In particular, among participants with strong uncertainty avoidance, customization positively influenced brand attitude when these participants experienced uncertainty, $B=1.61, \mathrm{SE}=0.55, t=2.93, p=.004,95 \% \mathrm{CI}=0.52$ to 2.70 . In other words, among participants with strong uncertainty avoidance, those who experienced uncertainty expressed more favorable attitudes toward a brand on a customized website than a noncustomized website. On the contrary, among participants with strong uncertainty avoidance, customization did not significantly influence brand attitude when these participants experienced 
certainty, $B=-0.82, \mathrm{SE}=0.49, t=-1.68, p=.096,95 \% \mathrm{CI}=-1.78$ to 0.15. In other words, among participants with strong uncertainty avoidance, those experienced certainty expressed similar attitudes toward a brand on a customized website and a non-customized website. Therefore, H1 was supported.

Hypothesis 2 predicts a serial mediation from perceived identity to sense of control between customization and brand attitude. A serial mediation analysis with 5,000 bootstrapped samples was conducted using model 6 of the PROCESS macro for SPSS (Hayes, 2012) with customization as the independent variable and brand attitude as the dependent variable. Noncustomization was coded as 1 , and customization was coded as 2 . Perceived identity and sense of control were added as the mediators. Product involvement was added as the covariate. The analysis didn't find the mediation effect of perceived identity $(B=-0.10, \mathrm{SE}=0.20,95 \% \mathrm{CI}=-$ 0.46 to 0.32$)$ or sense of control $(B=0.07, \mathrm{SE}=0.06,95 \% \mathrm{CI}=-0.06$ to 0.20$)$ respectively. However, the results revealed a significant serial mediation effect of the sequence from perceived identity to sense of control between customization and brand attitude $(B=0.20, \mathrm{SE}=$ $0.10,95 \% \mathrm{CI}=0.01$ to 0.40 ) (see Figure 3). Therefore, $\mathrm{H} 2$ was supported.

Insert Figure 3 about here.

\section{Discussion}

The present study analyzed the influence of interface customization on online brand evaluation among consumers with a strong versus weak tendency of uncertainty avoidance under psychological uncertainty. The findings indicated that the interplay between psychological uncertainty and customization was significant among participants with a strong tendency of uncertainty avoidance. In particular, those who experienced uncertainty evaluated a brand more favorably on a customized website than a non-customized website. However, such effects were 
not significant among participants with a weak tendency of uncertainty avoidance. Individuals with strong uncertainty avoidance normally perceive uncertain situations more threatening compared to those with weak uncertainty avoidance (Hofstede, 2001). The latter could tolerate psychological uncertainty to a larger extent than the former. As a result, in the current study, participants with strong uncertainty avoidance were in greater need of regaining perceptions of certainty by customizing the website when they experienced uncertainty compared to their counterparts with weak uncertainty avoidance. These findings offer interesting insights on the importance of media interface to online brand evaluation as well as the importance of contextual and individual factors to understanding the impact of customization.

\section{Theoretical Implications}

Uncertainty has been widely studied in consumer research. It is found to influence consumer responses to both innovative (Hoeffler, 2003) and non-innovative products (Johnson, 2004). While existing investigations of consumer uncertainty primarily consider uncertainty as a characteristic of the purchasing decision, such as the uncertainty of product performance, symbolic values or switching-cost (Hoeffler, 2003), limited attention has been paid to one's psychological uncertainty that may not be integral to product adoption. According to Faraji-Rad and Pham (2017), it is urgent to understand consumers' psychological uncertainty that is incidental to a purchase decision because product purchases do not occur in a vacuum and consumers are constantly affected by the external environment. Therefore, the present study adds to the emerging research stream that attempts to understand how psychological uncertainty affects consumer behavior by exhibiting the role of digital media in this process.

Another key contribution of this study is to identify the boundary conditions of the effects of customization which is a principal feature of digital interface. Previous research of 
customization has discovered that customization positively influences user responses. However, customization may not be beneficial in all conditions. Some other studies have attempted to recognize the moderators that impact the effects of customization, such as power usage (Sundar \& Marathe, 2010) and source credibility (Kang \& Sundar, 2016). The present study adds to this body of literature by demonstrating that psychological uncertainty and uncertainty avoidance could alter the influence of customization on brand evaluation. Future research of customization is thus suggested to take these factors into consideration when investigating other communication outcomes of customization.

This study also sheds light on why customization benefits brand evaluation. The mediation analysis found that neither perceived identity nor sense of control alone accounted for the impact of customization, but the sequence from perceived identity to sense of control. In other words, customization shapes online brand evaluation by helping consumers reaffirm their self-identity which in turn leads to increased sense of control that eventually benefits brand attitude. A scrutiny of previous customization studies identifies both consistent and conflicting evidence. For example, different from the present study, perceived identity was confirmed to mediate the impact of customization on participants' persistence in unsolvable anagram tasks (Kang \& Sundar, 2013) and systematic processing of online articles (Kang \& Sundar, 2016). In other studies, sense of control was not identified to directly mediate the relationship between customization and attitude (Sundar \& Marathe, 2010), but as a result of perceived identity (Marathe \& Sundar, 2011). To make sense of such mixed findings, the author suggests future investigations to pay more attention to the outcome measures. It seems that the direct mediation of perceived identity is more likely to occur when the outcome measures focus on people's cognitive responses (i.e., persistence in problem solving and systematic processing) rather than 
mere attitudes. The research context may also make a difference. The serial mediation was found in this study probably because both identity ambiguity and reduced control were the consequences of psychological uncertainty (see Hogg, 2001). Therefore, an important implication for future research is that the underlying processes of customization may vary depending on the other variables investigated in the research model.

Oh, Bellur, and Sundar (2015) suggested that users' digital experiences are determined by interface- and content-related factors together. Kalyanaraman and Wojdynski (2015) also called for more academic attention in the field of communication technology to the effects of media content in addition to technology features. However, content and interface may not be the only factors that define user experience in digital media. As revealed by the present study, media-use context (e.g., context-induced uncertainty) and individual traits (e.g., uncertainty avoidance) also play an important role in influencing online users' decision making. Therefore, future research on digital media is suggested to explore other contextual and individual-related factors. A complete theoretical framework for explaining digital media experience may include a variety of factors affiliated with media interface, content, context, and individual difference.

A growing number of studies in communication technology have emphasized the impact of cultural difference (Lee \& Sundar, 2015). For example, Li and Kalyanaraman (2013) confirmed that the cultural value of individualism-collectivism moderated individuals' responses to customization. Uncertainty avoidance is another important dimension in Hofstede's (2001) model of cultural values. Although it was measured at the individual level in the present study, it is believed that people from different countries that differ at the dimension of uncertainty avoidance may also respond to customization in different ways. Future studies are suggested to 
analyze uncertainty avoidance at the country level and explore other cultural differences in people's responses to various features of digital media.

The present study also supports the theoretical framework of the extended self (see Belk, 1988). A customized interface reflects a user's values and beliefs, and thus may be considered as his/her extended self. The findings that brand evaluation was influenced by interface customization in this study imply that the effects of extended self may be transferred to brand information presented on the media interface. The present study also advocates the principle of certainty compensation (see Hogg, 2007; Steele, 1988). When consumers feel uncertainty due to some contextual factors, customization may serve as an effective tool to help them regain perceptions of certainty. To the author's best knowledge, this is the first study that investigates digital interface as a strategy of certainty compensation.

\section{Practical Implications}

In addition to the theoretical implications discussed above, this study also provides several practical implications. First, designers of digital interface need to take contextual factors of media use and users' personal traits into consideration for interface design. That is to say, designers should not only consider the clients' needs, but also work closely with the consumer research team on the client side to fully understand the target users, including who they are and what their media use habits are. Second, marketing professionals are suggested to leverage customization strategically. As discovered in this study, customization may be generally beneficial in the situations of uncertainty. Therefore, marketing professionals should provide digital users with high levels of customization in situations that may give rise to consumers' psychological state of uncertainty. For example, the webpages that introduce completely new products or deal with consumers' complaints of unexpected delivery delay can be designed as 
highly customizable. Third, it is more important for marketing professionals to identify consumers who are in the status of uncertainty. Thanks to the powerful online analytics tools, like Google Analytics and Adobe Marketing Cloud, practitioners can analyze consumers' social media activities to find those who may feel strong uncertainty, including but not limited to consumers who move to a new place, start a new job, and experience changes in social relationships. Fourth, the strategic combination of customization and uncertainty may be more important in cultures of strong uncertainty avoidance. Therefore, the results of this study are potentially meaningful to practitioners of international marketing.

\section{Limitations and Future Research}

The study reported here does have some shortcomings that can be addressed in future investigations. First, following previous research of customization (e.g., Kang \& Sundar, 2013, 2016; Sundar \& Marathe, 2010), this study used an existing website to manipulate customization and delivered the brand article by adding a RSS feed. Future research may develop websites especially for the research purpose to have a better integration of the brand into the website. Second, this study used a student sample mainly because of the study setting (i.e., lab experiment). Although Millennials are a large part of the current digital users, the student sample may lower the representativeness of the results. The current sample contained more female students than male students. Such a gender skewness may affect the final results to some extent. Future research is thus suggested to use more representative samples. Third, brand attitude was the only dependent variable in this study. As discussed above, previous research has examined the impact of customization on a variety of communication outcomes. Future research may explore the interplay between customization and psychological uncertainty on people's cognitive and affective responses in the contexts rather than brand evaluation. 
In conclusion, the present study confirmed the impact of psychological uncertainty and uncertainty avoidance on the effects of customization. To answer the question raised in the title of this article, customization may benefit brand evaluation under psychological uncertainty only among consumers with a strong tendency of uncertainty avoidance. This study hopes to encourage future investigations in the fields of digital media and communication technology to focus on the contextual and individual factors that may shape users' digital experiences. 


\section{References}

Antioco, M., \& Kleijnen, M. (2010). Consumer adoption of technological innovations: Effects of psychological and functional barriers in a lack of content versus a presence of content situation. European Journal of Marketing, 44(11/12), 1700-1724. doi:

$10.1108 / 03090561011079846$

Belk, R. W. (1988). Possessions and the extended self. Journal of Consumer Research, 15(2), 139-168. doi: 10.1086/209154

Belk, R. W. (2013). Extended self in a digital world. Journal of Consumer Research, 40(3), 477500. doi: $10.1086 / 671052$

Campbell, J. D., Trapnell, P. D., Heine, S. J., Katz, I. M., Lavallee, L. F., \& Lehman, D. R. (1996). Self-concept clarity: Measurement, personality correlates, and cultural boundaries. Journal of Personality and Social Psychology, 70(1), 141-156. doi: $10.1037 / 0022-3514.70 .1 .141$

Castaño, R., Sujan, M., Kacker, M., \& Sujan, H. (2008). Managing consumer uncertainty in the adoption of new products: Temporal distance and mental simulation. Journal of Marketing Research, 45(3), 320-336. doi: 10.1509/jmkr.45.3.320

Dowling, G. R., \& Staelin, R. (1994). A model of perceived risk and intended risk-handling activity. Journal of Consumer Research, 21(1), 119-134. doi: 10.1086/209386

Faraji-Rad, A., \& Pham, M. T. (2017). On aesthetic pleasure: The uncertainty-reducing role of processing fluency. Journal of Consumer Research, 44(1), 1-21. doi:

$10.2139 /$ ssrn.2893645 
Grieve, P. G., \& Hogg, M. A. (1999). Subjective uncertainty and intergroup discrimination in the minimal group situation. Personality and Social Psychology Bulletin, 25(8), 926-940. doi: $10.1177 / 01461672992511002$

Griffith, D. A., Hu, M. Y., \& Ryans, J. K. (2000). Process standardization across intra-and intercultural relationships. Journal of International Business Studies, 31(2), 303-324. doi: 10.1057/palgrave.jibs. 8490908

Hayes, A. F. (2012). PROCESS: A versatile computational tool for observed variable mediation, moderation, and conditional process modeling. Retrieved from http://www.afhayes.com/public/process2012.pdf

Hoeffler, S. (2003). Measuring preferences for really new products. Journal of Marketing Research, 40(4), 406-420. doi: 10.1509/jmkr.40.4.406.19394.

Hofstede, G. (2001). Culture's consequences: Comparing values, behaviors, institutions, and organizations across nations. Thousand Oaks, CA: Sage Publications.

Hogg, M. A. (2000). Subjective uncertainty reduction through self-categorization: A motivational theory of social identity processes. European Review of Social Psychology, 11(1), 223-255. doi: 10.1080/14792772043000040

Hogg, M. A. (2001). Self-categorization and subjective uncertainty resolution: Cognitive and motivational facets of social identity and group membership. In J. P. Forgas, K. D. Williams, \& L. Wheeler (Eds.), The social mind: Cognitive and motivational aspects of interpersonal behavior (pp. 323-349). New York: Cambridge University Press.

Hogg, M. A. (2007). Uncertainty-identity theory. In M. P. Zanna (Ed.), Advances in experimental social psychology (Vol 39, pp. 69-126). San Diego, CA: Academic Press. 
Hogg, M. A., \& Adelman, J. (2013). Uncertainty-identity theory: Extreme groups, radical behavior, and authoritarian leadership. Journal of Social Issues, 69(3), 436-454. doi: 10.1111/josi.12023

Ibrahim, N., Shiratuddin, M. F., \& Wong, K. W. (2015). Instruments for Measuring the Influence of Visual Persuasion: Validity and Reliability Tests. European Journal of Social Sciences Education and Research, 4(1), 25-37. doi: 10.26417/ejser.v4i1.p25-37

Johnson, E. J. (2004). Rediscovering risk. Journal of Public Policy and Marketing, 23(1), 2-6. doi: 10.1509/jppm.23.1.2.30402

Kang, H., \& Sundar, S. S. (2013). Depleted egos and affirmed selves: The two faces of customization. Computers in Human Behavior, 29(6), 2273-2280. doi: 10.1016/j.chb.2013.05.018

Kang, H., \& Sundar, S. S. (2016). When self is the source: effects of media customization on message processing. Media Psychology, 19(4), 561-588. doi: $10.1080 / 15213269.2015 .1121829$

Kalyanaraman, S., \& Sundar, S. S. (2006). The psychological appeal of personalized content in web portals: does customization affect attitudes and behavior? Journal of Communication, 56(1), 110-132. doi: 10.1111/j.1460-2466.2006.00006.x

Kalyanaraman, S., \& Wojdynski, B. W. (2015). Affording control: How customization, interactivity, and navigability affect psychological responses to technology. In S. S. Sundar (Ed.), The handbook of the psychology of communication technology, (pp. 425445). Hoboken, NJ: Wiley-Blackwell. 
Kent, R. J., \& Allen, C. T. (1994). Competitive interference effects in consumer memory for advertising: The role of brand familiarity. The Journal of Marketing, 58(3), 97-105. doi: $10.2307 / 1252313$

Kleijnen, M., Lee, N., \& Wetzels, M. (2009). An exploration of consumer resistance to innovation and its antecedents. Journal of Economic Psychology, 30(3), 344-357. doi:10.1016/j.joep.2009.02.004

Lee, S., \& Sundar, S. S. (2015). Cosmetic customization of mobile phones: cultural antecedents, psychological correlates. Media Psychology, 18(1), 1-23. doi:

$10.1080 / 15213269.2013 .853618$

Li, C., \& Kalyanaraman, S. (2012). What if Web site editorial content and ads are in two different languages? A study of bilingual consumers' online information processing. Journal of Consumer Behaviour, 11(3), 198-206. doi: 10.1002/cb.1371

Li, C., \& Kalyanaraman, S. (2013). "I, Me, Mine” or “Us, We, Ours?”: The Influence of Cultural Psychology on Web-Based Customization. Media Psychology, 16(3), 272-294. doi: $10.1080 / 15213269.2013 .815049$

Littler, D., \& Melanthiou, D. (2006). Consumer perceptions of risk and uncertainty and the implications for behaviour towards innovative retail services: The case of internet banking. Journal of Retailing and Consumer Services, 13(6), 431-443. doi:10.1016/j.jretconser.2006.02.006

Marathe, S., \& Sundar, S. S. (2011). What drives customization? Control or identity? In Proceedings of the SIGCHI conference on human factors in computing systems (pp. 781790). New York: ACM. 
McGregor, I., Haji, R., Nash, K. A., \& Teper, R. (2008). Religious zeal and the uncertain self. Basic and Applied Social Psychology, 30(2), 183-188. doi: 10.1080/01973530802209251

McGregor, I., \& Marigold, D. C. (2003). Defensive zeal and the uncertain self: What makes you so sure? Journal of Personality and Social Psychology, 85(5), 838-852. doi: 10.1037/0022-3514.85.5.838

McGregor, I., Zanna, M. P., Holmes, J. G., \& Spencer, S. J. (2001). Compensatory conviction in the face of personal uncertainty: Going to extremes and being oneself. Journal of Personality and Social Psychology, 80(3), 472-488. doi: 10.1037//0022-3514.80.3.472

Oh, J., Bellur, S., \& Sundar, S. S. (2015). Clicking, assessing, immersing, and sharing: An empirical model of user engagement with interactive media. Communication Research. doi: $10.1177 / 0093650215600493$

Petty, R. E., Barden, J., \& Wheeler, S. C. (2002). The elaboration likelihood model of persuasion. In R. J. DiClemente, R. A. Crosby, \& M. C. Kegle (Eds.), Emerging theories in health promotion practice and research (pp. 71-99). San Francisco: Jossey-Bass.

Romppel, M., Herrmann-Lingen, C., Wachter, R., Edelmann, F., Düngen, H. D., Pieske, B., \& Grande, G. (2013). A short form of the General Self-Efficacy Scale (GSE-6): Development, psychometric properties and validity in an intercultural non-clinical sample and a sample of patients at risk for heart failure. GMS Psycho-Social-Medicine, 10, 1-7. doi: $10.3205 / \mathrm{psm} 000091$

Rosenberg, M. (1965). Society and the adolescent self-image. Princeton, NJ: Princeton University Press.

Sorrentino, R. M., Hodson, G., \& Huber, G. L. (2001). Uncertainty orientation and the social mind: Individual differences in the interpersonal context. In J. P. Forgas, K. D. Williams, 
\& L. Wheeler (Eds.), The social mind: Cognitive and motivational aspects of interpersonal behavior (pp. 199-227). New York: Cambridge University Press.

Steele, C. M. (1988). The psychology of self-affirmation: Sustaining the integrity of the self. In L. Berkowitz (Ed.), Advances in experimental social psychology (pp. 261-302). San Diego, CA: Academic Press.

Steele, C. M., \& Liu, T. J. (1983). Dissonance processes as self-affirmation. Journal of Personality and Social Psychology, 45(1), 5-19. doi: 10.1037/0022-3514.45.1.5

Sundar, S. S. (2008). Self as source: Agency and customization in interactive media. In E. A. Konijn, S. Utz, M. Tanis, \& S. B. Barnes (Eds.), Mediated interpersonal communication (pp. 58-74). New York: Routledge.

Sundar, S. S., \& Marathe, S. S. (2010). Personalization versus customization: The importance of agency, privacy, and power usage. Human Communication Research, 36(3), 298-322. doi: 10.1111/j.1468-2958.2010.01377.x

Sundar, S. S., Oh, J., Bellur, S., Jia, H., \& Kim, H-S. (2012). Interactivity as self-expression: A field experiment with customization and blogging. In Proceedings of the SIGCHI Conference on Human Factors in Computing Systems (pp. 395-404), New York: ACM.

Swinyard, W. R. (1993). The effects of mood, involvement, and quality of store experience on shopping intentions. Journal of Consumer Research, 20(2), 271-280. doi: $10.1086 / 209348$

Szmigin, I., \& Foxall, G. (1998). Three forms of innovation resistance: the case of retail payment methods. Technovation, 18(6-7), 459-468. doi: 10.1016/S0166-4972(98)00030-3 
Valenzuela, A., Dhar, R., \& Zettelmeyer, F. (2009). Contingent response to self-customization procedures: Implications for decision satisfaction and choice. Journal of Marketing Research, 46(6), 754-763. doi: 10.1509/jmkr.46.6.754

Van den Bos, K. (2009). Making sense of life: The existential self trying to deal with personal uncertainty. Psychological Inquiry, 20(4), 197-217. doi: 10.1080/10478400903333411

Van den Bos, K., \& Lind, E. A. (2002). Uncertainty management by means of fairness judgments. Advances in Experimental Social Psychology, 34, 1-60. doi: 10.1016/S00652601(02)80003-X

Van den Bos, K., Poortvliet, P. M., Maas, M., Miedema, J., \& Van den Ham, E. J. (2005). An enquiry concerning the principles of cultural norms and values: The impact of uncertainty and mortality salience on reactions to violations and bolstering of cultural worldviews. Journal of Experimental Social Psychology, 41(2), 91-113. doi: 10.1016/j.jesp.2004.06.001

Waddell, T. F., Zhang, B., \& Sundar, S. S. (2016). Human-computer interaction. In C. R. Berger, \& M. E. Rolof (Eds.), International encyclopedia of interpersonal communication. Malden, MA: Wiley.

Webster, D. M., \& Kruglanski, A. W. (1997). Cognitive and social consequences of the need for cognitive closure. European Review of Social Psychology, 8(1), 133-173. doi: $10.1080 / 14792779643000100$

Wind, J., \& Rangaswamy, A. (2001). Customerization: The next revolution in mass customization. Journal of Interactive Marketing, 15(1), 13-32. doi: 10.1002/15206653(200124) 
Wu, L. (2017). Relationship building in nation branding: The central role of nation brand commitment. Place Branding and Public Diplomacy, 13(1), 65-80. doi: $10.1057 /$ pb. 2015.16

Yoo, B., Donthu, N., \& Lenartowicz, T. (2011). Measuring Hofstede's five dimensions of cultural values at the individual level: Development and validation of CVSCALE. Journal of International Consumer Marketing, 23(3-4), 193-210. doi: $10.1080 / 08961530.2011 .578059$

Zajonc, R. B. (1980). Feeling and thinking: Preferences need no inferences. American Psychologist, 35(2), 151-175. doi: 10.1037/0003-066X.35.2.151

Zaichkowsky, J. L. (1994). The personal involvement inventory: Reduction, revision, and application to advertising. Journal of Advertising, 23(4), 59-70. doi:

$10.1080 / 00913367.1943 .10673459$ 


\section{Appendix}

Table 1. Correlations between measured variables in the pretest

\begin{tabular}{lllll}
\hline & $\begin{array}{l}\text { Perceived } \\
\text { certainty }\end{array}$ & $\begin{array}{l}\text { Self-concept } \\
\text { clarity }\end{array}$ & Self-efficacy & Self-esteem \\
\hline $\begin{array}{l}\text { Perceived } \\
\text { certainty }\end{array}$ & 1 & & & \\
$\begin{array}{l}\text { Self-concept } \\
\text { clarity }\end{array}$ & 0.24 & 1 & & \\
Self-efficacy & 0.20 & $0.32^{*}$ & 1 & \\
Self-esteem & 0.15 & $0.57^{* *}$ & $0.52^{* *}$ & 1 \\
\hline Mean & 7.22 & 5.70 & 6.66 & 6.47 \\
SD & 1.64 & 1.56 & 1.34 & 1.40 \\
\hline
\end{tabular}

Note: ${ }^{*} p<.05,{ }^{* *} p<.01$

Table 2. Correlations between measured variables in the main experiment

\begin{tabular}{|c|c|c|c|c|c|c|}
\hline & $\begin{array}{l}\text { Perceived } \\
\text { certainty }\end{array}$ & $\begin{array}{l}\text { Perceived } \\
\text { identity }\end{array}$ & $\begin{array}{l}\text { Sense of } \\
\text { control }\end{array}$ & $\begin{array}{l}\text { Brand } \\
\text { attitude }\end{array}$ & $\begin{array}{l}\text { Uncertainty } \\
\text { avoidance }\end{array}$ & $\begin{array}{l}\text { Product } \\
\text { involvement }\end{array}$ \\
\hline $\begin{array}{l}\text { Perceived } \\
\text { certainty }\end{array}$ & 1 & & & & & \\
\hline $\begin{array}{l}\text { Perceived } \\
\text { identity }\end{array}$ & -0.10 & 1 & & & & \\
\hline $\begin{array}{l}\text { Sense of } \\
\text { control }\end{array}$ & -0.08 & $0.60 * *$ & 1 & & & \\
\hline Brand attitude & -0.16 & -0.01 & 0.10 & 1 & & \\
\hline $\begin{array}{l}\text { Uncertainty } \\
\text { avoidance }\end{array}$ & -0.08 & 0.16 & $0.20^{*}$ & $0.21 *$ & 1 & \\
\hline $\begin{array}{l}\text { Product } \\
\text { involvement }\end{array}$ & 0.10 & -0.06 & -0.16 & $0.27 * *$ & -0.11 & 1 \\
\hline Mean & 6.13 & 4.63 & 6.69 & 7.18 & 7.66 & 5.23 \\
\hline SD & 2.38 & 2.22 & 1.50 & 1.43 & 1.22 & 1.88 \\
\hline
\end{tabular}

Note: $* p<.05, * * p<.01$ 
Figure 1. The example with customized webpage (brand article was shown at the upper left corner; information that revealed geographic locations was erased)

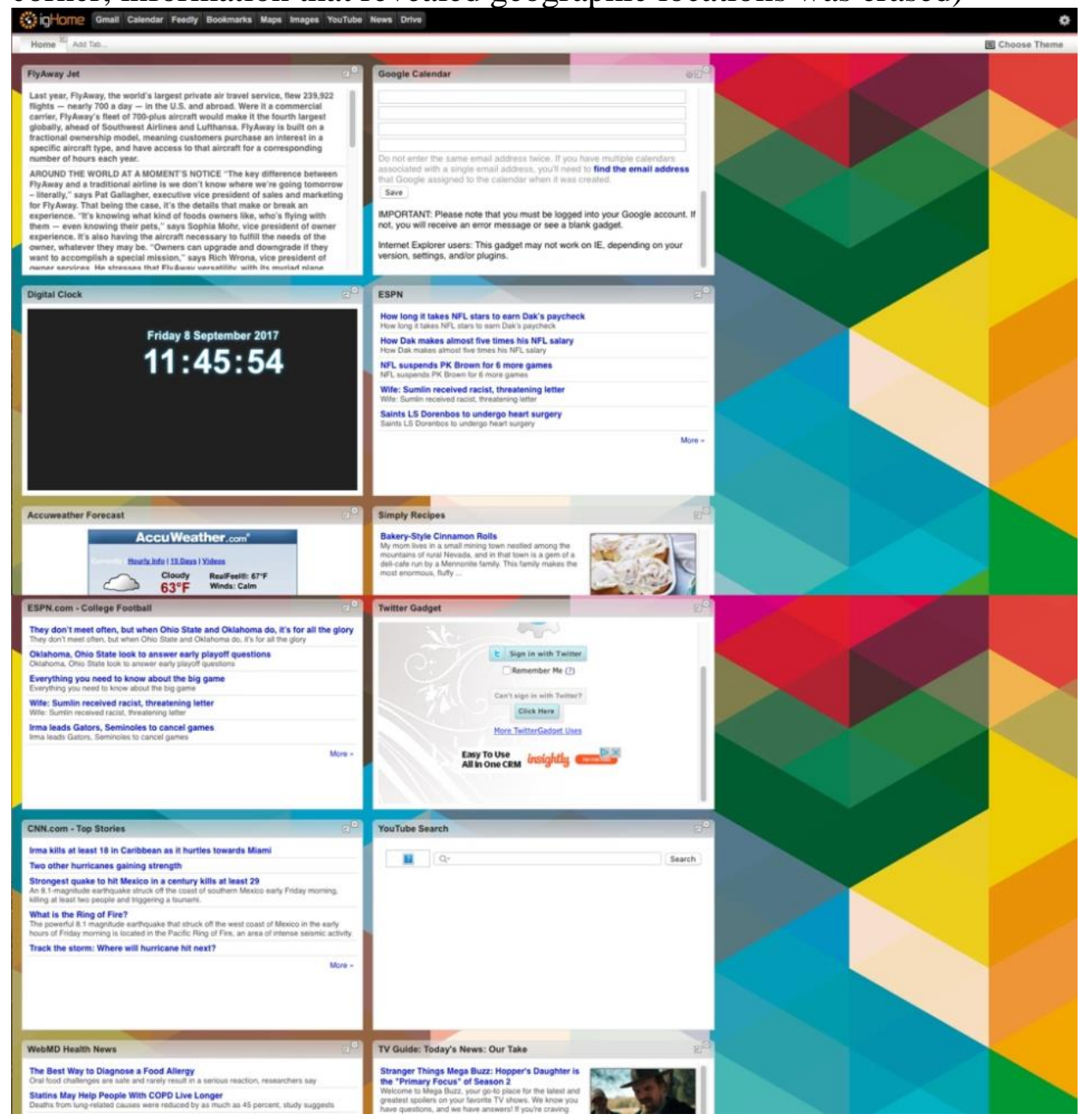

Figure 2. The example with non-customized webpage (brand article was shown at the upper left corner; information that revealed geographic locations was erased)

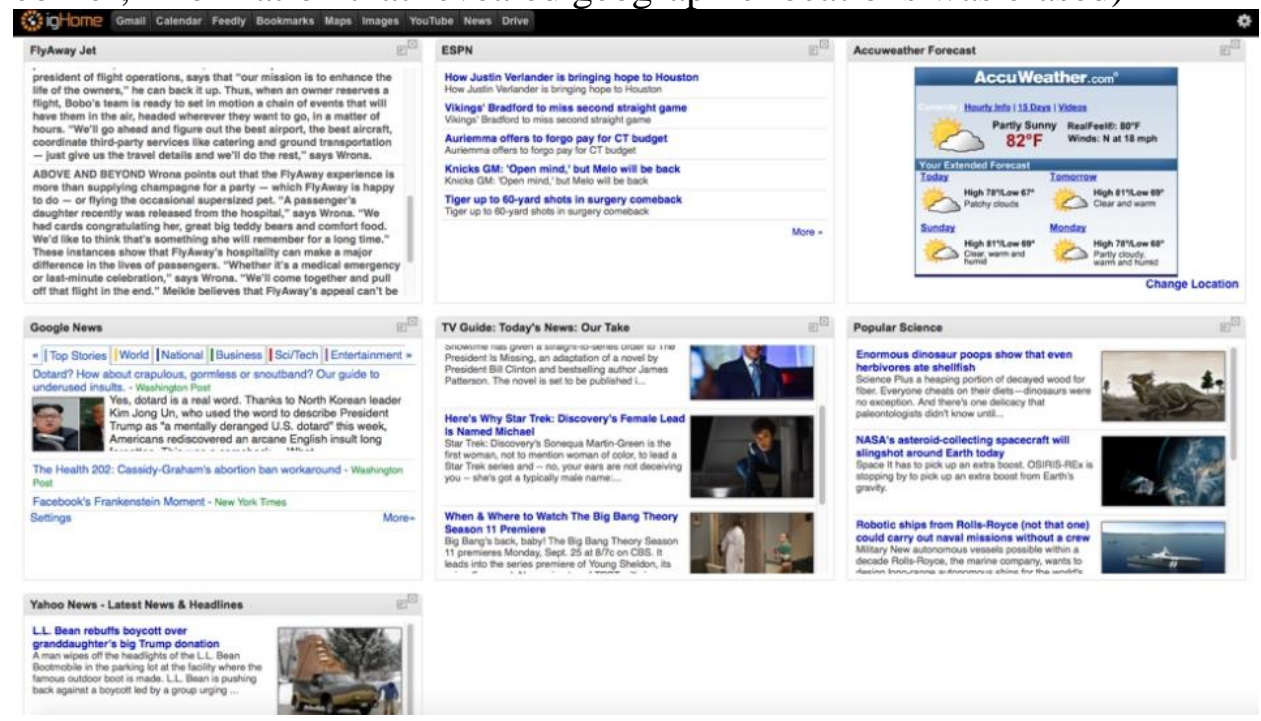


Figure 3. The mediation effect of perceived identity and sense of control

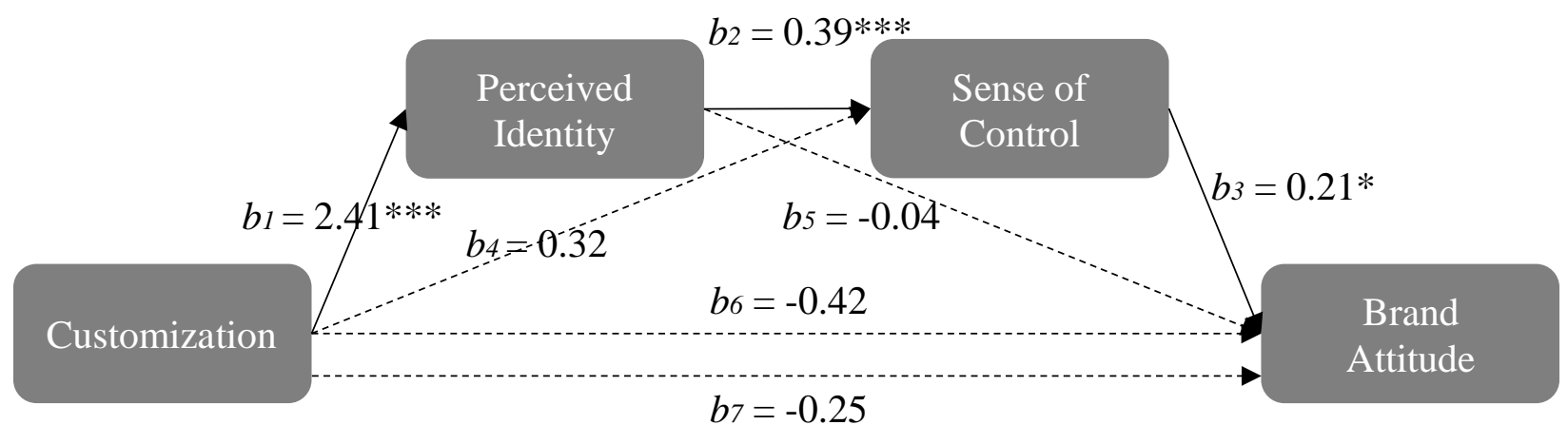

Note: $* * * p<.001, * * p<.01, * p<.05$; Dashed paths indicate nonsignificant relationships; Product involvement was added as a covariate in this model.

i Although uncertainty avoidance was measured after the manipulations, a two-way ANOVA analysis (with psychological uncertainty and interface customization as the independent variables and uncertainty avoidance as the dependent variable) found that there was no main effect of psychological uncertainty, $F(1,117)=0.22, p=.638$, no main effect of interface customization, $F(1,117)=1.89, p=.172$, nor interaction effect between psychological uncertainty and interface customization, $F(1,117)=0.63, p=.430$ on uncertainty avoidance. 